\title{
Structural Responses of Flexible Pavement Subjected to Different Axle Group Loads ${ }^{\dagger}$
}

\author{
Auckpath SAWANGSURIYA ${ }^{1, *}$, Thanongsak IMJAI ${ }^{2}$ and \\ Suphawut MALAIKRISANACHALEE ${ }^{3}$
}

\author{
${ }^{1}$ Bureau of Road Research and Development, Department of Highways, Bangkok 10400, Thailand \\ ${ }^{2}$ School of Engineering and Technology, Walailak University, Nakhonsithammarat 80161, Thailand \\ ${ }^{3}$ Faculty of Engineering, Kasetsart University, Bangkok 10900, Thailand
}

('Corresponding author's e-mail: sawangsuriya@gmail.com)

Received: 11 June 2019, Revised: 4 November 2019, Accepted: 8 December 2019

\begin{abstract}
This study presents the structural responses of flexible pavement which were subjected to different axle group loads. Three types of axle group loads, e.g. single axle-dual wheel, tandem axle-dual wheel, and tridem axle-dual wheel, were applied over the field for the instrumented trial section. The corresponding structural responses were measured using a series of embedded instrumentations e.g. pressure cells, asphalt strain gauges, strain gauges, thermocouples, moisture sensors etc. A 3-dimensional (3-D) finite-element analysis (FEA) model and the multi-layer linear-elastic analysis (LEA) were developed to estimate structural responses which were then compared with the field measurement data. Both FEA and LEA assumed the pavement layer materials to be homogeneous, isotropic, and linearelastic. The elastic moduli of pavement layers were determined from the falling weight deflectometer (FWD) based on the backcalculation procedure. Results from the analysis indicated that both FEA and LEA were in good agreement with the field measurement results with some exceptions for strains under the asphalt concrete surface.
\end{abstract}

Keywords: Structural response, Flexible pavement, Axle load, Finite-element, Instrumentation

\section{Introduction}

The long-term pavement performance (LTPP) is becoming a major concern for most road maintenance and rehabilitation authorities and agencies. To efficiently estimate the pavement structural responses under the traffic loads and volumes, it is necessary to provide adequate pavement structural design and analysis in companion with numerical modeling based on the mechanistic approach. Such practice is somewhat a challenge task for academics and practitioners in the pavement engineering communities.

A finite-element analysis (FEA) has been widely adopted in the recently developed mechanistic design and performance analysis of the pavement system because of its versatile implication of mechanical characterization [1-5]. In particular, the flexible pavement structure is typically considered as a layered system where each layer is practically assumed to be homogenous, isotropic, and linear-elastic. The thicknesses and the material properties (e.g. modulus of elasticity and Poisson's ratio) varied from each layer.

†Presented at the $2^{\text {nd }}$ International Symposium on Construction Innovation Research \& PhD Symposium: July 18-19, 2019. 
http://wjst.wu.ac.th

The objective of this study is to examine the structural responses of flexible pavement under different types of axle group loads. The 3-dimensional (3-D) finite-element analysis (FEA) and the multilayer linear-elastic analysis (LEA) were performed to calculate the pavement structural responses subjected to 3 types of axle group load, e.g. single axle-dual wheel, tandem axle-dual wheel, and tridem axle-dual wheel. The actual responses of a field instrumented trial flexible pavement section were also measured using a series of embedded instrumentations e.g. pressure cells, asphalt strain gauges, strain gauges, thermocouples, moisture sensors etc. Both 3-D FEA model and LEA were developed to estimate structural responses, which were then compared with the field measurement data. Under the assumptions of homogenous, isotropic, and linear-elastic layer system, both FEA and LEA results were expected to be consistent with the field measurement results.

\section{Literature review}

Recent developments in computer programming and experimental techniques have offered many advantages to the FEA of the pavement structural responses due to a variety of loading conditions. Such FEA is also becoming an excellent tool for developing and understanding the physical problems of complex pavement system. A number of commercial FEA computer software with different model type selections were reported in chronological order as follows.

Cho et al. [1] utilized the general purposes finite-element packages (ABAQUS ${ }^{\mathrm{TM}}$ ) to develop the pavement model of hot-mix asphalt overlay on the rigid pavement. Three types of models, i.e., 3dimensional (3-D), plane strain, and axisymmetric finite-element model, were selected for a proper traffic loading simulation on the basis of linear-elastic analysis. Results from the FEA indicated that both 3-D and axisymmetric finite-element models gave reasonable structural responses. In addition, the study also suggested that an axisymmetric model was more suitable than a 3-D model when the computational time and memory were considered.

Kim [2] reported that $\mathrm{ABAQUS}^{\mathrm{TM}}$, $\mathrm{ANSYS}^{\mathrm{TM}}$, and $\mathrm{ADINA}^{\mathrm{TM}}$ provided proper analyses of various engineering problems. Although pavement structural modeling has developed dramatically in recent years, pavement analysis with general-purpose programs has not yet been applied in the flexible pavement modeling. In Kim's study, the 3-D finite-element model by user material subroutine (UMAT) for $\mathrm{ABAQUS}^{\mathrm{TM}}$ was employed and compared with the axisymmetric model generated by GT-Pave program. The results showed no major difference between these two programs regarding their structural responses.

Ban et al. [3] utilized $\mathrm{ABAQUS}^{\mathrm{TM}}$ for the prediction model development of the pavement performance and its service life. In their study, three types of models including axisymmetric, 2-D plane strain, and 3-D finite-element model were considered. The results of these models under multiple wheel loads were compared to a layered elastic analysis program named JULEA. Consequently, the axisymmetric model by ABAQUS ${ }^{\mathrm{TM}}$ was proven to be efficient and accurate. The pavement performance and its service life from the axisymmetric model were also compared with the Mechanistic-Empirical Pavement Design Guide (M-E PDG).

Haselbach et al. [4] developed the FEA model of a pervious concrete pavement. ABAQUS ${ }^{\mathrm{TM}}$ was used to model and analyze a section of the pervious pavement under a static load. The developed model was validated by comparing the results with EverFE ${ }^{\mathrm{TM}}$ - a specific software for pavement structural analysis.

Zhu et al. [5] utilized UMAT in $\mathrm{ABAQUS}^{\mathrm{TM}}$ to investigate the asphalt pavement rutting. The developed model was applied to simulate the 3-stage rutting behavior of a typical asphalt pavement with the semi-rigid base under different traffic loads. The results showed that heavy traffic load not only induced larger rut depth, but also increased the rutting development.

Past studies reported that the FEA was suitable for the analysis of complex pavement problems [6]. The 3-D FEA model was selected in this study because it was anticipated to be more accurate than the 2D FEA model and was able to capture the pavement responses in all directions. For the pavement structural analysis in this study, the pavement layer system was assumed to be homogenous, isotropic, and linear-elastic. 


\section{Materials and methods}

Description of field trial section and pavement structure

A field trial flexible pavement section is located on Highway No.32 at STA $121+250$ (South Bound), adjacent to a weight-in-motion (WIM) system and approximately $700 \mathrm{~m}$ prior to Suppaya Stationery Weight Stations, Chainat, Thailand. The pavement structure consisted of $200 \mathrm{~mm}$ asphalt concrete (AC) surface, $200 \mathrm{~mm}$ crushed rock base, $200 \mathrm{~mm}$ soil-aggregate subbase, and subgrade (Figure 1).

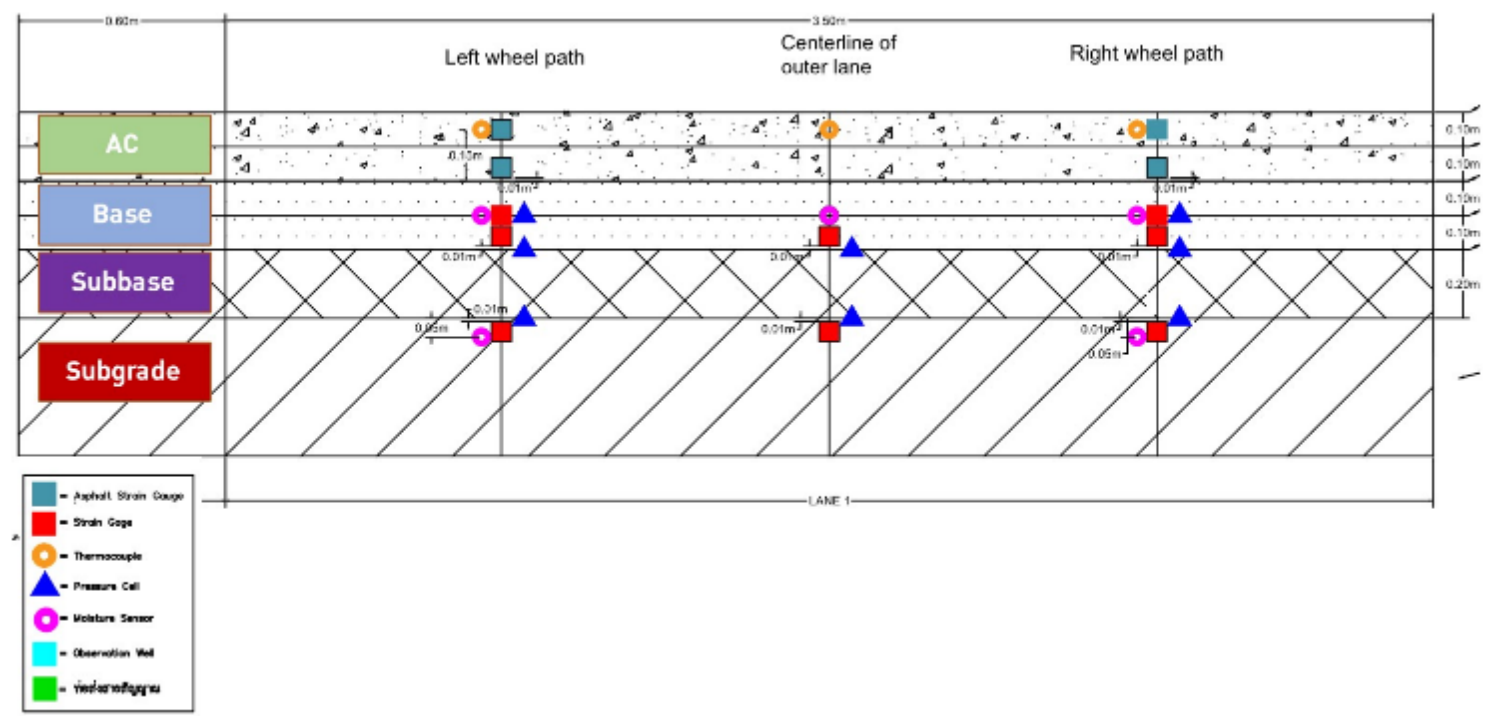

Figure 1 Typical cross-section of field instrumented trial flexible pavement section.

\section{Constitutive model for AC surface and granular layers}

For simplicity, the AC surface was considered to be linear-elastic in this study and its modulus of elasticity (E) and Poisson's ratio are summarized in Table 1. The granular layers (e.g. base, subbase, and subgrade) were modeled as elastic perfectly plastic using a Mohr-Coulomb failure criteria and an associated flow rule [6,7]. The modulus of elasticity (E) for pavement layer was determined from the Falling Weight Deflectometer (FWD). The backcalculated E values and assumed Poisson's ratio ( $v$ ) are summarized in Table 1.

Table 1 Material properties.

\begin{tabular}{cccccc}
\hline Pavement layer & $\begin{array}{c}\text { Backcalculated E } \\
\text { (MPa) }\end{array}$ & $\begin{array}{c}\text { Assumed } \\
\mathbf{v}\end{array}$ & $\begin{array}{c}\text { Unit weight } \\
\left(\mathbf{k N} / \mathbf{m}^{3}\right)\end{array}$ & $\begin{array}{c}\text { Cohesion* } \\
\text { (kPa) }\end{array}$ & $\begin{array}{c}\text { Friction angle* }^{*} \\
\text { (degree) }\end{array}$ \\
\hline $\begin{array}{c}\text { Asphalt concrete } \\
\text { (AC) surface }\end{array}$ & 1,745 & 0.35 & 25 & - & - \\
$\begin{array}{c}\text { Crushed rock base } \\
\text { Soil-aggregate }\end{array}$ & 170 & 0.35 & 22.7 & 30 & 43 \\
$\quad$ subbase & 249 & 0.35 & 22.7 & 30 & 43 \\
$\quad$ Subgrade & 163 & 0.40 & 19.8 & 8 & 36 \\
\hline
\end{tabular}

* Referenced from Moayedi et al. [8] 
http://wjst.wu.ac.th

\section{Model geometry, mesh size, and boundary condition}

Eight-node linear brick solid elements with reduced integration (C3D8R) available in ABAQUS [9] were used to generate the trial pavement section because these elements yielded better solutions than linear interpolation elements [10]. The "Hard Contact" friction model available in ABAQUS was adopted in the analysis to model the contact behavior between the layer materials. Figure 2 shows the FEA model and FEA mesh of the trial pavement section. The FE model had $2 \mathrm{~m}$ wide, $4 \mathrm{~m}$ long, and $1 \mathrm{~m}$ thick. The mesh size of $50 \mathrm{~mm}$ was selected according to the sensitivity analysis [11]. Conventional kinematic boundary conditions were adopted, i.e., roller supports along both side of vertical boundaries and fixed supports along the bottom of horizontal boundary.

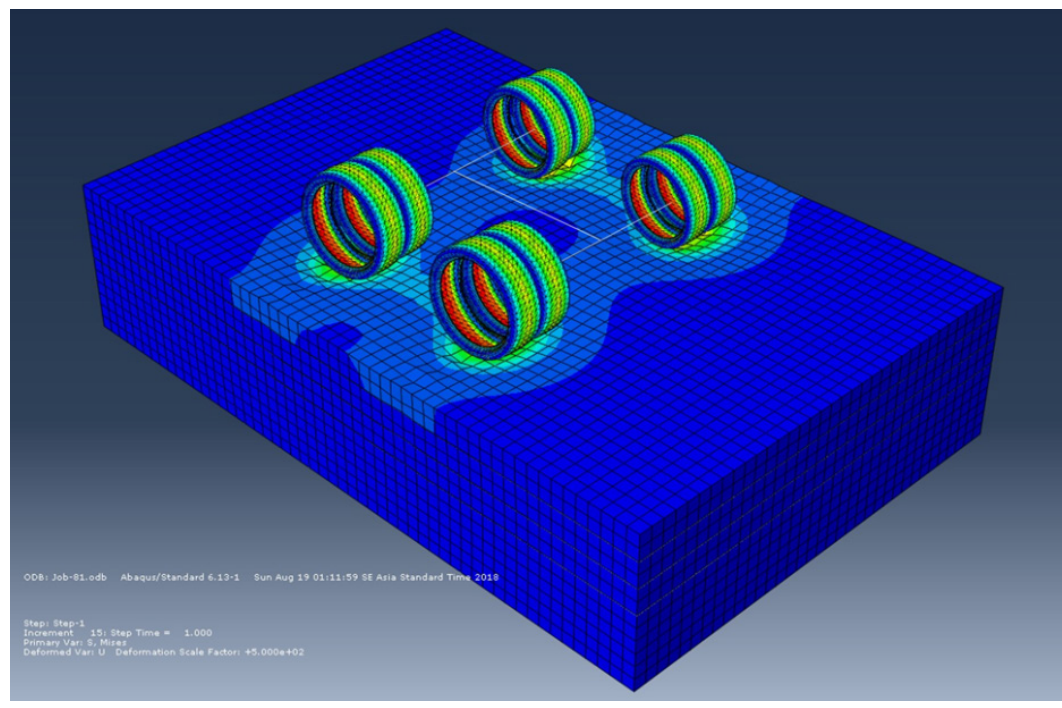

Figure 2 FEA model and FEA mesh of the trial pavement section.

Wheel load, tire pressure, and contact area

A contact area is a function of tire pressure, wheel geometry, and axle load. It can be expressed as 2 semi-circles, which can be further simplified by an equivalent rectangle as suggested by Huang [12]. The simplified contact area was calculated to be $0.5 \mathrm{~L}^{2}$ having a width of $0.6 \mathrm{~L}$ and a length of $0.9 \mathrm{~L}$. Three types of axle group loads, e.g. single axle-dual wheel, tandem axle-dual wheel, and tridem axle-dual wheel, were applied over a field instrumented trial section. A summary of the equivalent contact area for each type of axle group load along with their wheel load information is summarized in Table 2.

Table 2 Wheel load information.

\begin{tabular}{ccccccc}
\hline Axle Group Load & $\begin{array}{c}\text { Axle Load } \\
(\mathbf{k N})\end{array}$ & $\begin{array}{c}\text { Number of } \\
\text { Wheel per } \\
\text { Axle }\end{array}$ & $\begin{array}{c}\text { Wheel } \\
\text { Load } \\
(\mathbf{k N})\end{array}$ & $\begin{array}{c}\text { Tire Pressure } \\
(\mathbf{M P a})\end{array}$ & $\begin{array}{c}\text { Area* } \\
\left(\mathbf{m m}^{\mathbf{2}}\right)\end{array}$ & $\begin{array}{c}\text { Length* } \\
(\mathbf{m m})\end{array}$ \\
\hline Single axle-dual wheel & 110 & 4 & 27.5 & 0.83 & 32,492 & 249 \\
Tandem axle-dual wheel & 100 & 4 & 25.0 & 0.90 & 27,241 & 228 \\
Tridem axle-dual wheel & 85 & 4 & 21.3 & 0.90 & 23,155 & 211 \\
\hline
\end{tabular}

* Referenced from Huang [12] 
http://wjst.wu.ac.th

\section{Multi-layer linear-elastic analysis}

In companion with the FEA, the LEA was performed to examine the responses of a linear-elastic multi-layered structure. The analysis was based on the assumption that the layered materials were homogenous, isotropic, and linear-elastic. The applied vertical load was uniformly distributed over a circular area. The input parameters for the LEA including material properties, layer thickness, and load geometry were identical to the FEA.

\section{Embedded instrumentation}

The corresponding pavement structural responses were measured using a series of embedded instrumentation including 8 asphalt strain gauges, 16 strain gauges, 16 pressure cells, 1 observation well, 8 thermocouples, and 16 moisture sensors were installed within the flexible pavement structure. The data logger, field data processing system, and power supply system were also equipped at this trial section. Details of field instrumental system are provided in the Department of Highways (DOH) report [11]. Figures 1 and 3 illustrate a typical cross-section of this trial section and an installation of field instrumental system, respectively.

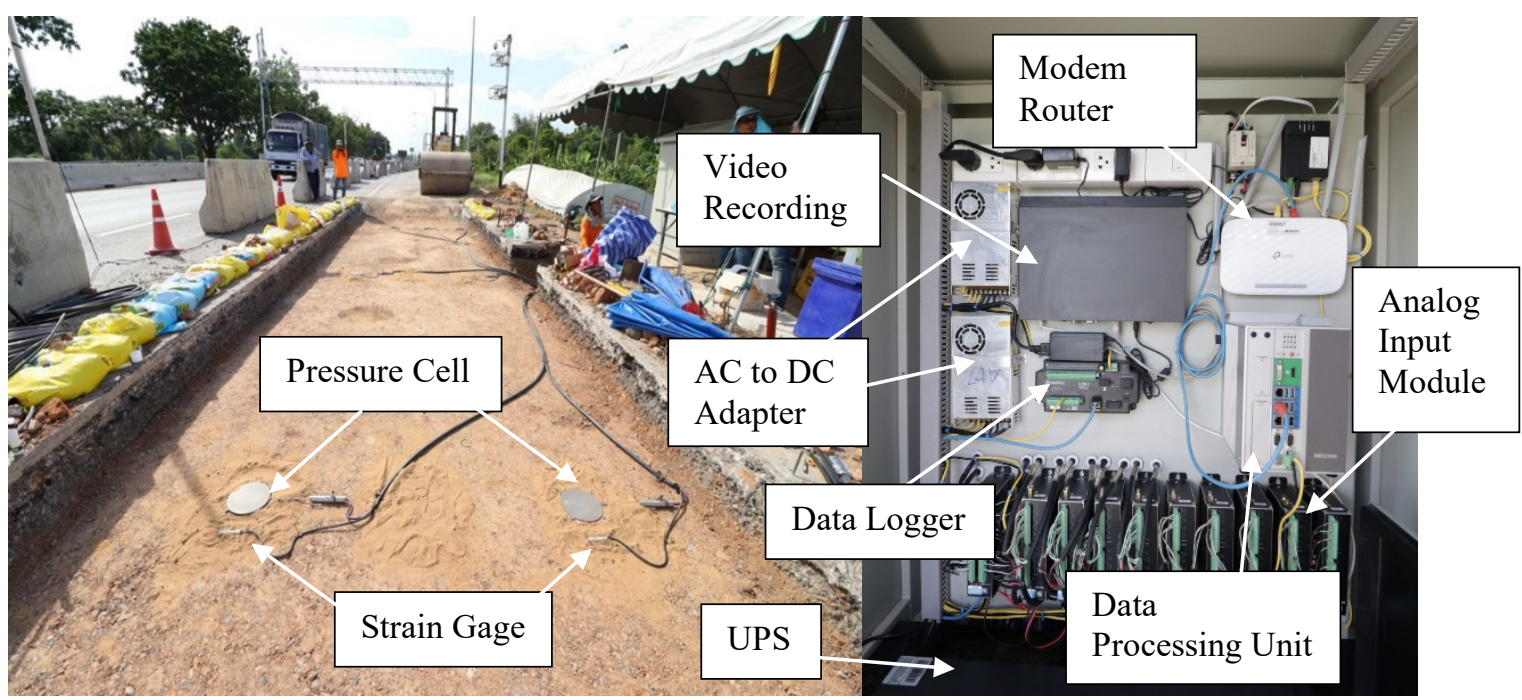

Figure 3 Installation of field instrumental system.

\section{Results and analysis}

A 3-D FEA was employed in this study to examine the structural responses (e.g. stress and strain) of flexible pavement under different types of axle group loads. In addition, the multi-layer linear elastic analysis (LEA) of a layered elastic system was also used to calculate and compare the structural responses with the FEA. Both FEA and LEA were based on the assumption that every layer material exhibited linear-elastic, homogeneous, and isotropic. Both analyses had similar backcalculated moduli, assumed Poisson's ratio, and the applied wheel loads. Plots of vertical stresses, vertical strains, horizontal strains in perpendicular to traffic direction, and horizontal strains in parallel to traffic direction as a function of depth were illustrated in Figures 4 - 6. Note also that only responses right under the applied wheel load were reported herein. It was found that both FEA and LEA agreed considerably well.

The results of the field measurement data were shown in Figures 7 - 9. The measured structural responses under a single axle-dual wheel, a tandem axle-dual wheel, and a tridem axle-dual wheel were presented herein along with the theoretical values based on the closed form solutions by Boussinesq, 
Odemark, and Burmister. It should be noted that the backcalculated moduli from the FWD, assumed Poisson's ratio, and the applied wheel loads which were input in the closed form solutions were identical to those input in the FEA and LEA. The plots indicated that most measured responses were consistent with the theoretical values with some exceptions for the strains under the AC surface. The reason for this discrepancy might be because the backcalculated (actual) moduli of AC surface and crushed rock base were smaller than the expected moduli (design values), although the construction and quality control processes were in accordance with the standard and specification. As expected, both FEA and LEA provided similar results because the layer materials were modeled as homogeneous, isotropic, and linearelastic. Furthermore, both FEA and LEA tended to match reasonably well with the measured responses.
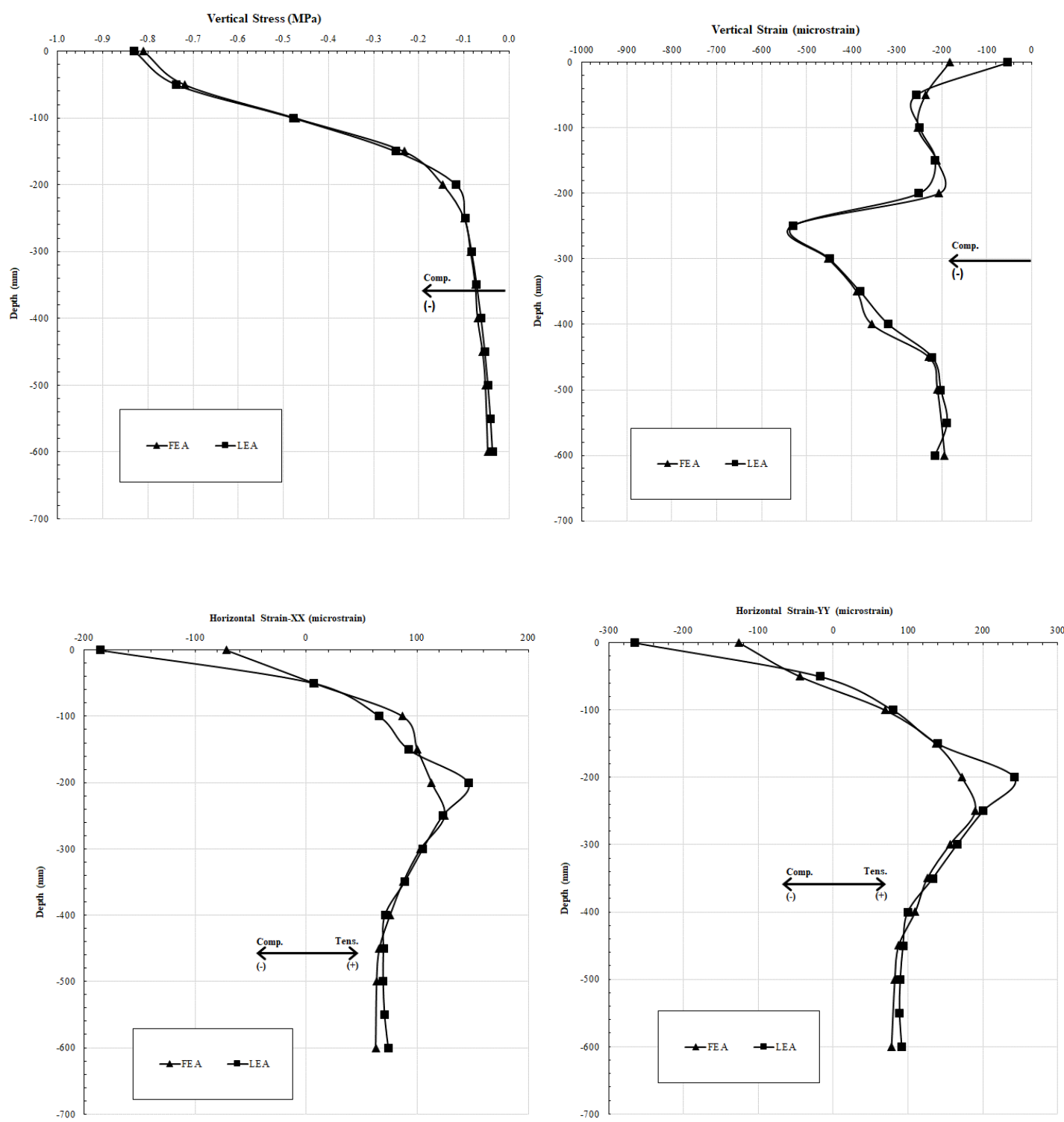

Figure 4 Structural responses of FEA and LEA under a single axle-dual wheel. 

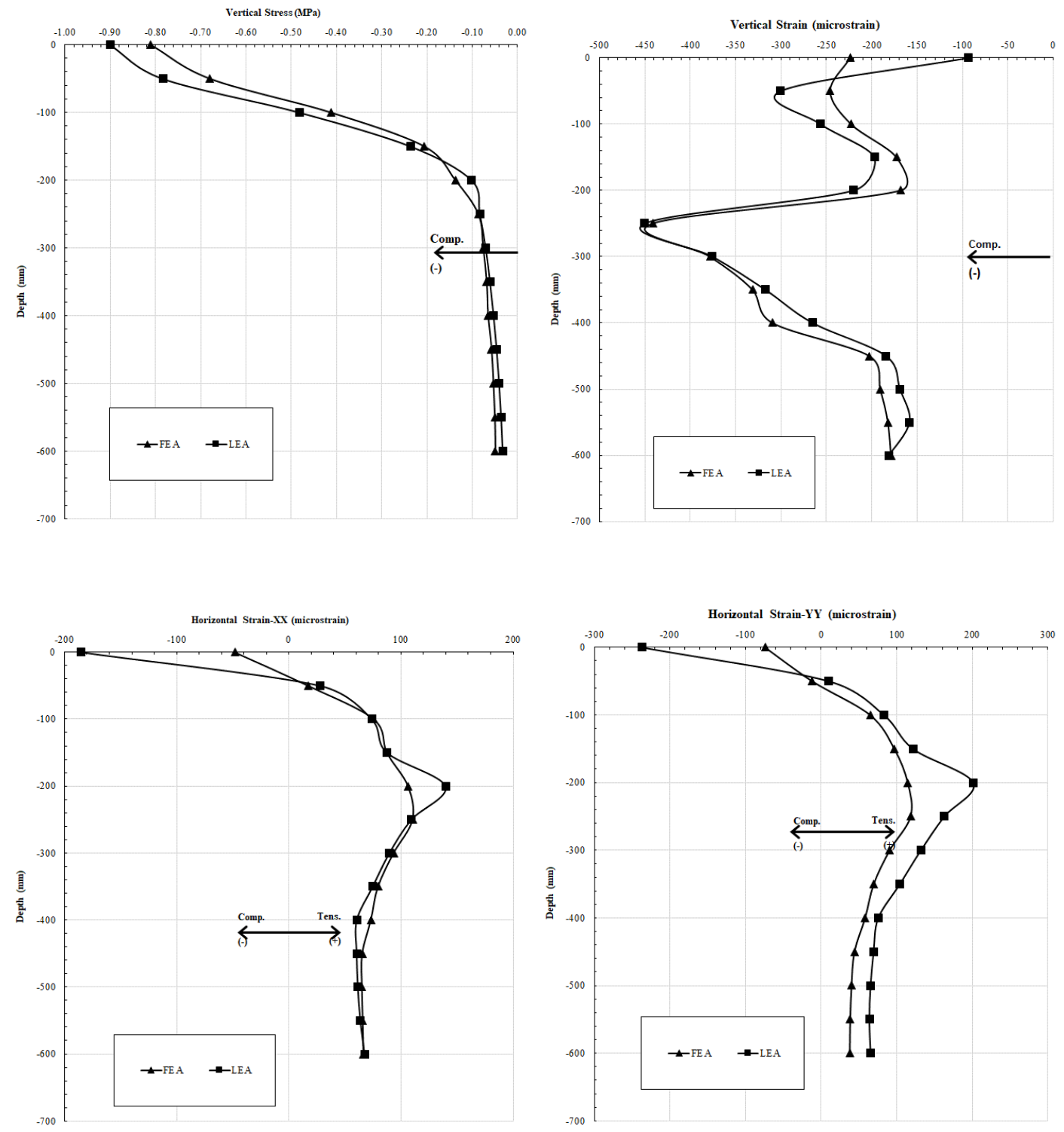

Figure 5 Structural responses of FEA and LEA under a tandem axle-dual wheel. 

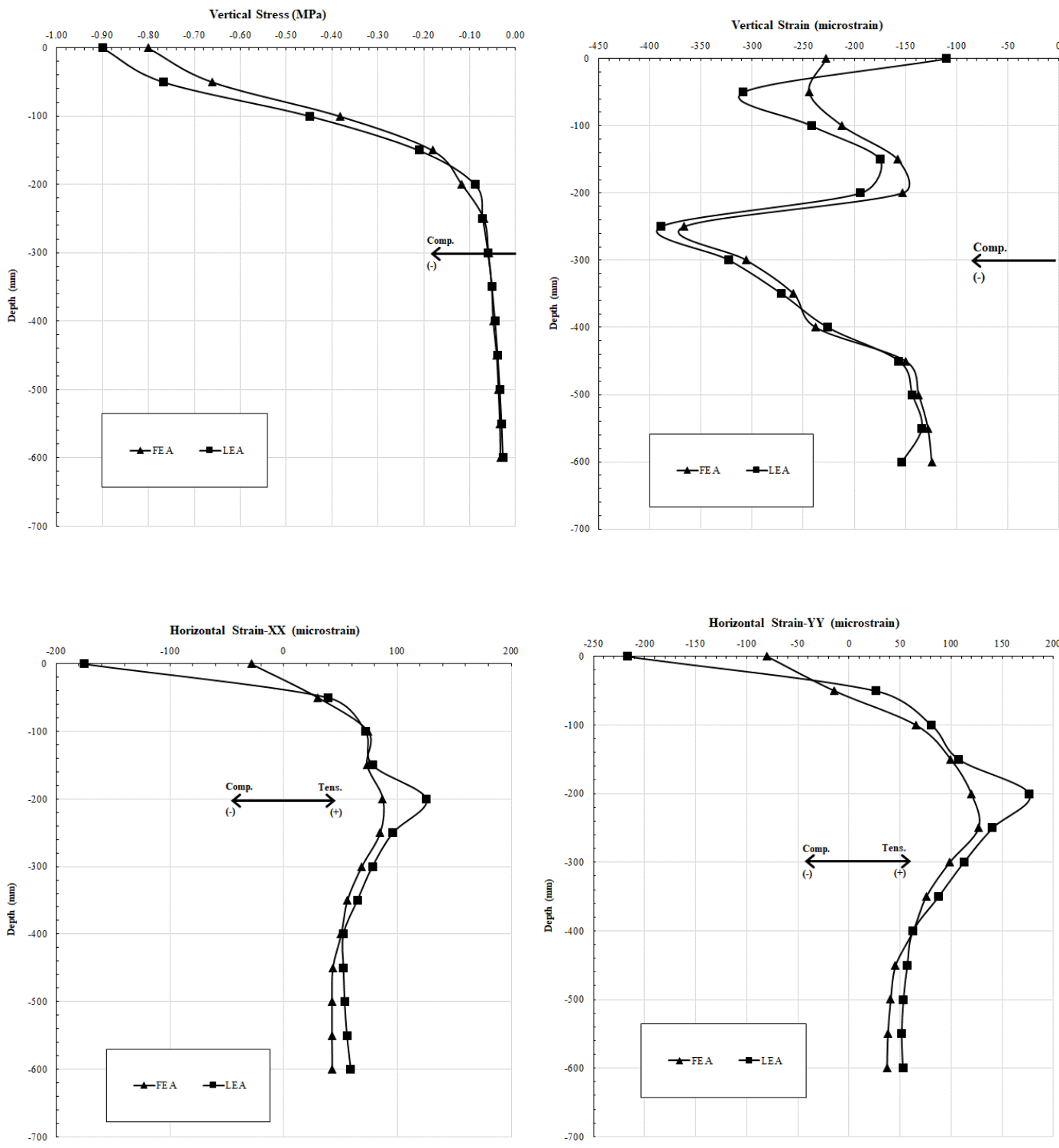

Figure 6 Structural responses of FEA and LEA under a tridem axle-dual wheel. 


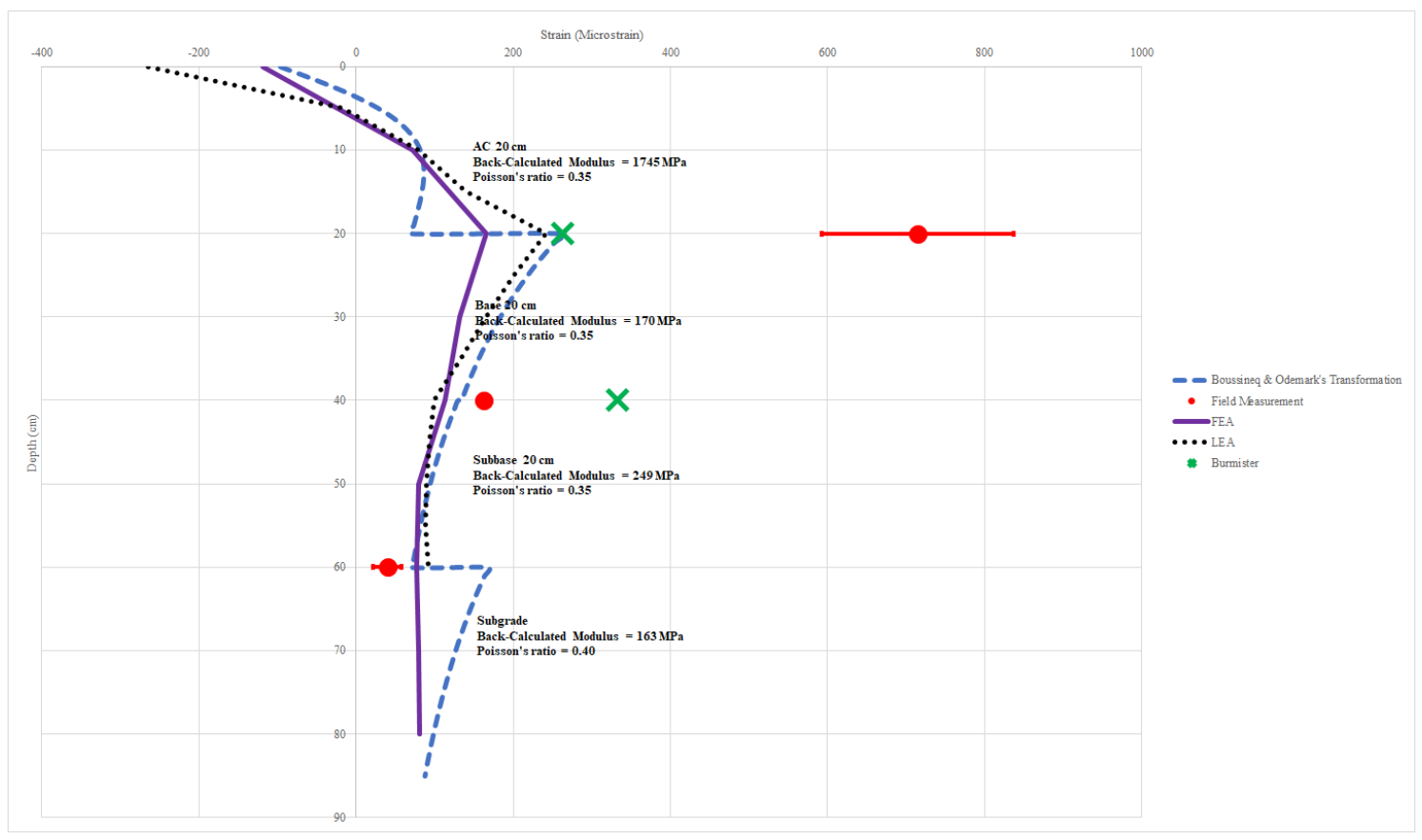

Figure 7 Measured and calculated structural responses under a single axle-dual wheel.

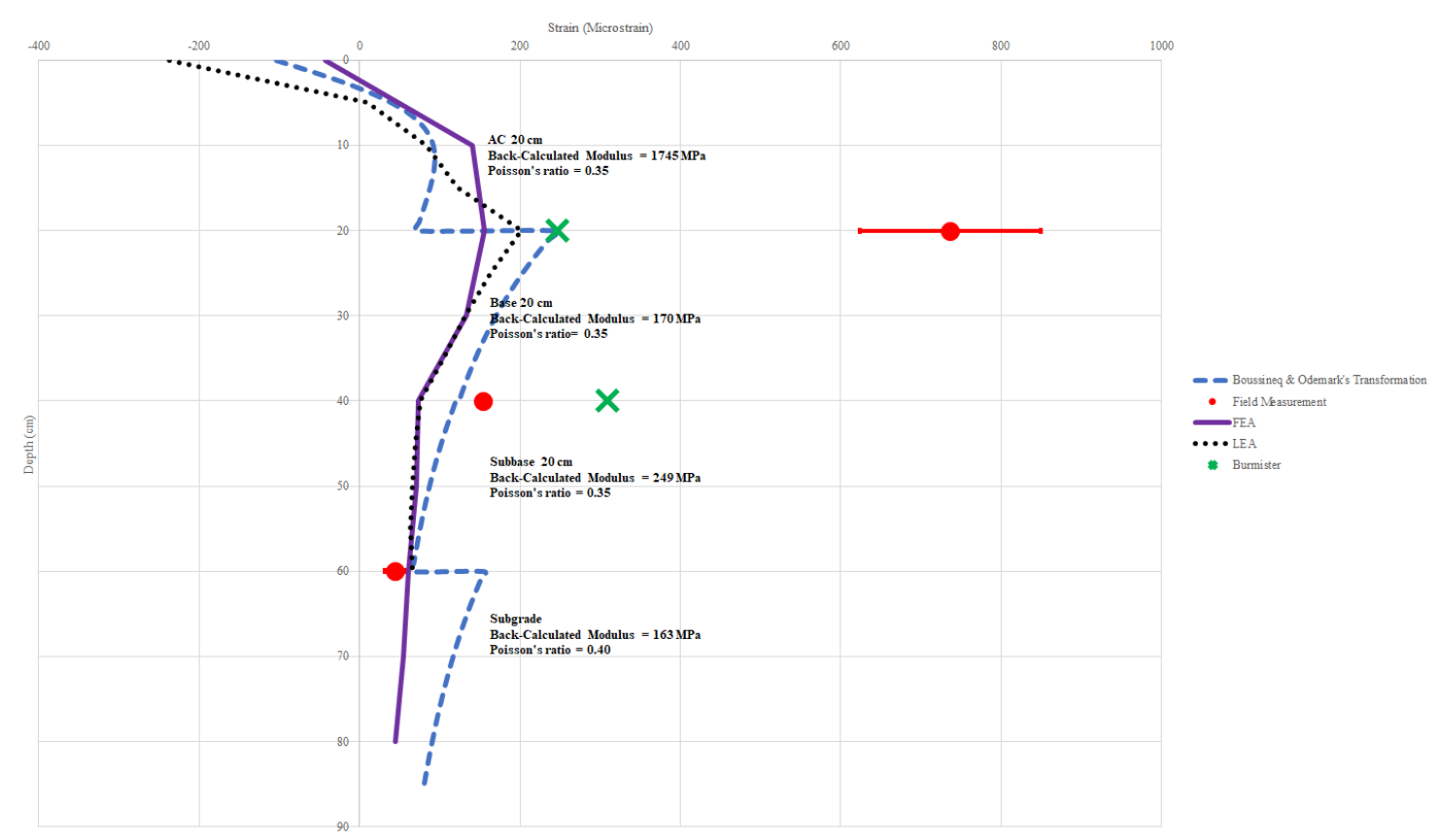

Figure 8 Measured and calculated structural responses under a tandem axle-dual wheel. 


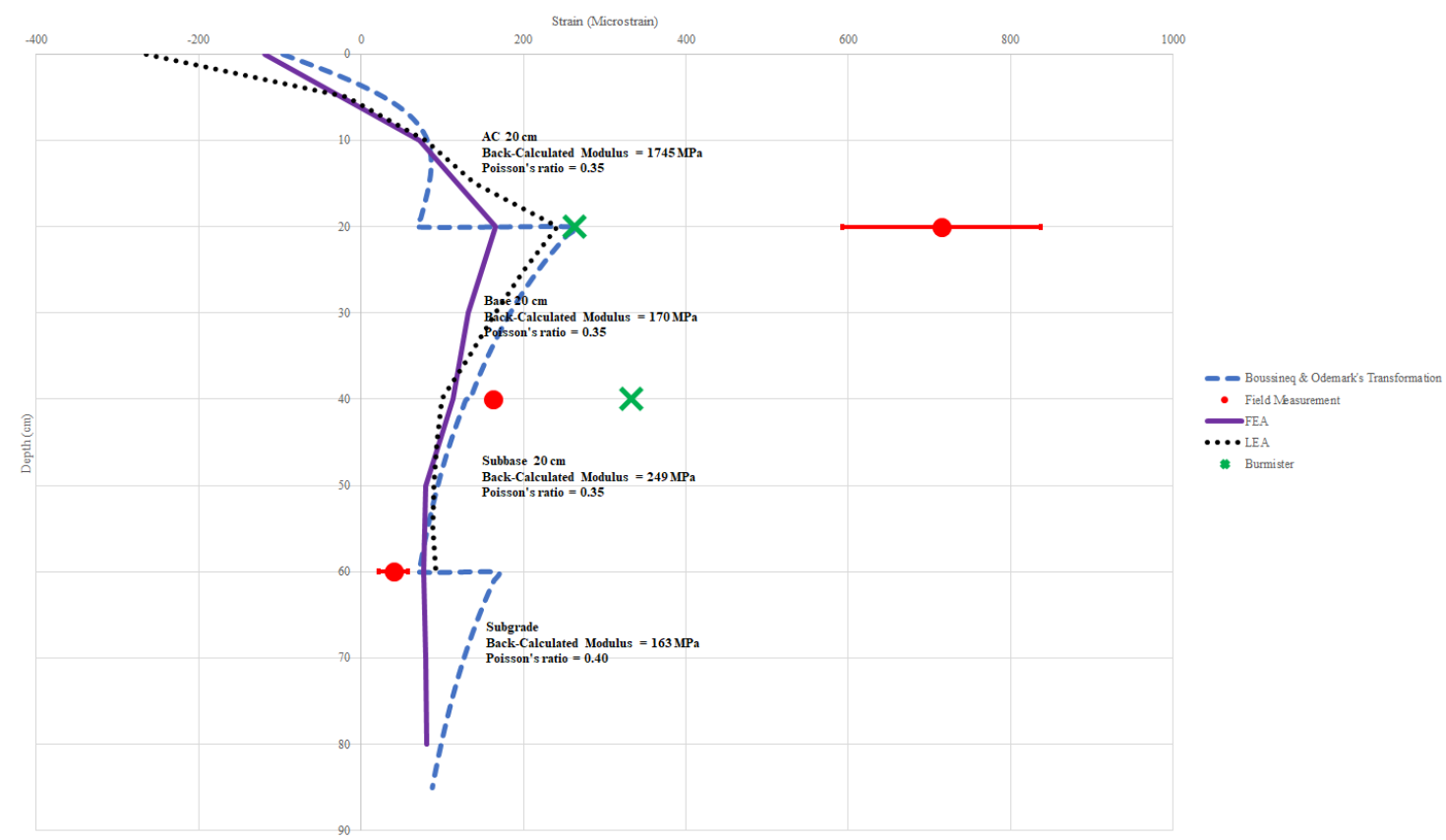

Figure 9 Measured and calculated structural responses under a tridem axle-dual wheel.

\section{Conclusions}

This study examined the structural responses of flexible pavement under different types of axle group loads. The 3-dimensional (3-D) finite-element analysis (FEA) and the multi-layer linear-elastic analysis (LEA) were performed to calculate pavement structural responses subjected to 3 types of axle group load, e.g. single axle-dual wheel, tandem axle-dual wheel, and tridem axle-dual wheel, over a field instrumented trial section. The responses were measured using a series of embedded instrumentations e.g. asphalt strain gauges, strain gauges, pressure cells, thermocouples, moisture sensors etc. The 3-D FEA model and the LEA were developed to estimate pavement responses and then compared with the field measurement data. Both FEA and LEA assumed the pavement layer materials to be homogeneous, isotropic, and linear-elastic. The elastic moduli of pavement layers were determined from the falling weight deflectometer based on backcalculation procedure. The results from the analysis indicated that both FEA and LEA were comparable, while the measured data tended to be consistent with the closed form solutions and numerical analyses with some exceptions for strains under the AC surface. The reason for this discrepancy might be because the backcalculated (actual) moduli of AC surface and crushed rock base were smaller than the expected moduli (design values), although the construction and quality control processes were in accordance with the standard and specification. Nonetheless, the study suggested that the structural responses in terms of vertical stresses, vertical strains, and horizontal strains from the FEA were in good agreement with the LEA for a given backcalculated moduli. Therefore, further measured responses could be estimated from both FEA and LEA. Finally, based on the preliminary verification of field measurement and numerical result in this study, the long-term pavement performance (LTPP) of the field instrumented trial section can be further monitored and evaluated. The FE model with non-linearity is definitely useful; thus, it required further investigation in order to predict the long-term pavement performance e.g. rutting behavior under the actual traffic loading condition, where the application of LEA will be very limited for this case. The research effort is currently in progress and the comprehensive LTPP study is still underway. 


\section{Acknowledgement}

This study was part of research project under the supervision of Bureau of Road Research and Development, Department of Highways (DOH). The project was carried out by the collaboration between DOH and Faculty of Engineering, Kasetsart University during 2017 - 2018.

\section{References}

[1] Y Cho, BF Mccullough and J Weissmann. Consideration on finite element method application in pavement structural analysis. Transport. Res. Rec. 1996; 1539, 96-101.

[2] M Kim. 2007, Three-dimensional Finite Element Analysis of Flexible Pavement Considering Nonlinear Pavement Foundation Behavior. Ph.D. Dissertation, University of Illinois at UrbanaChampaign, USA.

[3] H Ban, S Im and Y Kim. Truck Loading on Design and Analysis of Asphaltic Pavement Structures. Mid-America Transportation Center, 2010.

[4] L Haselbach, F William and CA Alam. Three-dimensional finite element modelling of pervious concrete pavement: vertical porosity destribution approach. Int. J. Res. Eng. Tech. 2013; 12, 767-77.

[5] C Zhu, X Li, J Pei, J Chen and J Zhang. Characterizing the three-stage rutting behavior of asphalt pavement with semi-rigid base by using UMAT in ABAQUS. Construct. Build. Mater. 2017; 140, 496-507.

[6] SW Perkins. Numerical Modeling of Geosynthetic Reinforced Flexible Pavement. FHWA/MT-01003/99160-2. Montana Department of Transportation, 2001.

[7] HL Ling and Z Liu. Performance of geosynthetic-reinforced asphalt pavement. J. Geotech. Geoenviron. Eng. 2001; 127, 177-84.

[8] H Moayedi, SK Arun and BK Huat. Effect of geogrid reinforcement location in paved road improvement. Electron. J. Geotech. Eng. 2009; 14, 1-11.

[9] ABAQUS. FEA Software and User's Manual Version 6.5. Hibbitt, Karlsson and Sorensen. Rhode Island, USA, 2009.

[10] J Hua. 2000, Finite Element Modeling and Analysis of Accelerated Pavement Testing Devices and Phenomenon. Ph.D. Dissertation, Purdue University, USA.

[11] DOH. 2018, Research and Development of Department of Highways Pavement Structure. Final Report. Department of Highways, Thailand.

[12] YH Huang. Pavement Analysis and Design. Pearson Prentice-Hall, New Jersey, 2004. 